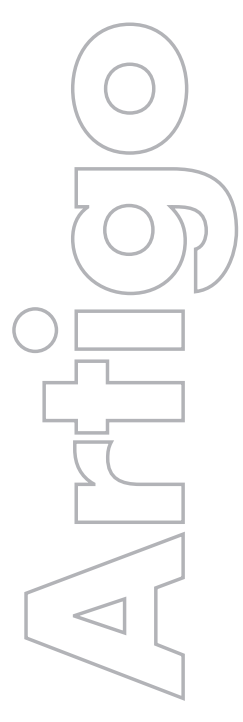

revista

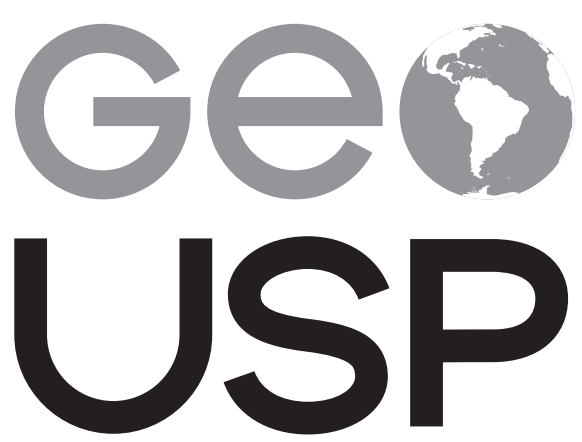

espaço e tempo

Volume $21 \cdot n^{\circ} 2$ (2017)

ISSN 2179-0892
Ser lugar e ser território como experiências $d$

o ser-no-mundo: um exercício de existencialismo geográfico

\author{
Angelo Serpa \\ UFBA
}

p. $586-600$

Como citar este artigo:

SERPA, A. Ser lugar e ser território como experiências do ser-no-mundo: um exercício de existencialismo geográfico. Geousp - Espaço e Tempo (Online), v. 21, n. 2, p. 586-600, agosto. 2017. ISSN $2179-0892$.

Disponível em: < http://www.revistas.usp.br/geousp/ article/view/125427> . doi: 10.11606/issn.2179-0892. geousp.2017.125427.

\section{(c) $(1)(9$}

Este artigo está licenciado sob a Creative Commons Attribution 4.0 License. 


\title{
Ser lugar e ser território como experiências do ser-no-mundo: um exercício de existencialismo geográfico
}

\section{Resumo}

Este ensaio busca aprofundar uma abordagem existencialista dos conceitos de lugar e território assumindo o pressuposto de que eles remetem, antes de tudo, a experiências geográficas que ora se distinguem, ora se aproximam e carregam em si a marca do espaço vivido. Para esta análise, parte-se do conceito de geograficidade - a base pré-consciente e pré-conceitual da geografia - assumindo também que, antes de qualquer conceituação ou estratégia de representação conceitual, as pessoas são seres essencialmente espaciais e que viver é produzir/experienciar espaço. $\bigcirc$ ensaio está dividido em seis seções: a introdução, uma problematização da dialética entre interior e exterior e seu desdobramento numa abordagem de como lugar e território se exprimem como modos geográficos de existência no espaço público; nas duas últimas seções, reflete-se sobre o papel do corpo nos processos de apropriação do espaço e sobre como ser lugar e ser território se exprimem como facetas do ser-no-mundo em seu sentido mais político.

Palavras-chave: Lugar. Território. Ser-no-mundo. Ser lugar. Ser território.

\section{Being place and being territory as experiences of being-in-the-world: an exercise in geographic existentialism}

\begin{abstract}
This essay aims to deepen an existentialist approach to the concepts of place and territory, assuming that place and territory refer first and foremost to geographical experiences that are sometimes different from each other and that sometimes can come close to each other. Those experiences, in turn, carry in themselves life space's mark. The concept of "geographicality" (géographicité) - the preconscious and preconceptual basis of Geography - is brought into to the intended analysis, assuming that even before any conceptualization or strategy of conceptual representation, human beings are spatial beings in their essence and that living is producing / experiencing space. The essay is divided into six sections, including the Introduction and then a discussion on the problematic of the dialectic
\end{abstract}


between interior and exterior, unfolded in an approach of how place and territory express themselves as geographic modes of existence in the public space. The last two sections are devoted to a reflection on the role of the body in the processes of appropriation of space and how being place and being territory express themselves as facets of being-in-the-world in its most political sense.

Keywords: Place. Territory. Being-in-the-world. Being place. Being territory.

\section{Introdução}

Esse ensaio pretende problematizar os conceitos de lugar e território à luz de uma inquietação recorrente do autor em relação à sua operacionalização nas pesquisas e reflexões geográficas. Como fio condutor da problematização aqui pretendida resgata-se o conceito de geograficidade de Eric Dardel, assumindo seu princípio de base, de que, antes mesmo de qualquer conceituação ou estratégia de representação conceitual, os seres humanos são seres espaciais em sua essência, e que viver é produzir/experienciar espaço (Dardel, 2011; Relph, 1979, 1985, 2012; Lefebvre, 2000, 2004, 2006; Merleau-Ponty, 2004, 2006).

Para Dardel (2011, p. 1-2), "a inquietude geográfica precede e sustenta a ciência objetiva [...] uma relação concreta liga o homem à Terra, uma geograficidade (géographicité) do homem como modo de existência". Aqui, a geograficidade é compreendida como a base pré-consciente e pré-conceitual da geografia, como nos lembra Relph (1979, p. 2), que pode embasar descrições compreensivas da experiência geográfica, já que "tendo identificado e interpretado estruturas de experiência, torna-se possível examinar os caminhos pelos quais se constituem, onde elas se originam, como elas se desenvolvem e se transformam" (Relph, 1979, p. 5).

Ou seja, lugar e território, antes de tudo, remetem a experiências geográficas que por vezes se distinguem, por vezes se aproximam, experiências que, por seu lado, carregam em si a marca do espaço vivido, revelando também que os conceitos utilizados em geografia são "modos geográficos de existência" (Marandola Jr., 2012), que se realizam nas situações cotidianas, posteriormente abstraídas em representações do espaço. ${ }^{1}$ Sim, estamos aqui diante das contradições e convergências dos espaços de representação, espaços vividos, na concepção de Henri Lefebvre (2000).

Ser lugar e/ou ser território? Em que situações somos e nos manifestamos como lugar? Ou em que situações somos e nos manifestamos como território? Ou melhor: que experiências primeiras fundamentam o ser-no-mundo como lugar ou território?

Em geral, assistimos nas últimas décadas à consolidação do conceito de território em geografia, sua generalização como conceito norteador de pesquisas e reflexões, não só no Brasil, mas também no exterior, em especial nos países latino-americanos. De igual modo, o

1 sentido de representação adotado aqui extrapola o de ideologia, ou melhor, evidencia a diferença fundamental entre os conceitos, como discutidos por Lefebvre (2006) em A presença e a ausência, onde o autor procura mostrar a diferença entre produto e obra e discute o papel das representações na constituição de ambos. Lefebvre estabelece o conceito de representação como a melhor forma de explicitar as relações de mediação entre sujeito/objeto, ser/pensamento, ideal/real etc., defendendo a distinção necessária entre as representações que impedem/impossibilitam o surgimento do "possível" daquelas que podem possibilitar sua emergência. 
conceito de lugar vem sendo resgatado e operacionalizado em pesquisas e reflexões geográficas, indicando sua retomada frente a outros conceitos geográficos, como região e território, em alguns momentos se contrapondo, em outros se aproximando deles.

Também se convencionou, entre os geógrafos, que lugar é espaço vivido e que território é espaço de poder, o que pressupõe uma generalização (muitas vezes incômoda por ser insatisfatória!) que oculta mais do que revela a maneira como ambos os conceitos se manifestam existencialmente, como experiência (em geral não explicitada), antes do exercício intelectual e de qualquer estratégia de representação teórica:

Há, de início, a apresentação dos fatos e dos conjuntos de fatos, o modo de percebê-los e de agrupá-los. Em seguida, há a re-presentação, a interpretação dos fatos. Entre esses dois momentos, e em cada um deles, intervêm desconhecimentos, mal-entendidos. $\bigcirc$ cegante (os conhecimentos que se adotam dogmaticamente) e o cegado (o desconhecido) são complementares na cegueira (Lefebvre, 2004, p. 39, grifos no original).

Questiona-se se seria possível viver sem o exercício do poder ou sobre a possibilidade da existência do poder sem a experiência do poder. Parte-se aqui da premissa que o poder (ou sua ausência) é um fenômeno vivido e que o vivido também manifesta as relações de poder. Afinal, como esses conceitos se apresentam a nós como experiências geográficas? $\bigcirc$ território não é também vivido? E o lugar não está também subordinado ao (exercício do) poder?

Para desenvolver este ensaio, um ponto de partida fundamental é a questão dos limites e das fronteiras e de como limites e fronteiras se manifestam em nossas relações com o outro no cotidiano e nas mais diversas escalas. A noção de limite em geografia indica uma espécie de agenciamento que coloca em contato dois espaços justapostos e que pode permitir o surgimento de uma interface. Esta definição coloca a noção de limite em relação com a noção de interação espacial, a interação nula (ou quase nula, resultante da ausência ou da inexpressividade de interações espaciais) representando um caso particular de relação.

Como lembram Lévy e Lussault (2003) os limites se constituem como "objetos geográficos" plenos, que se apresentam no espaço com diferentes conteúdos e estilos. Acrescentemos que os limites colocam em evidência continuidades e descontinuidades manifestas nos processos de produção e reprodução do/no espaço. Por outro lado, a fronteira é ela mesma um espaço (uma faixa) e "tende a provocar uma dicotomia entre as identidades territoriais, conforme se pertence ou não a um território. De fato, no que concerne à diferença cultural, os embates de fronteira que afloram tanto podem ser conflituosos como consensuais" (Almeida, 2012, p. 149).

Então, mais que associar a priori os conceitos de lugar e território a qualidades específicas (lugar = vivido; território = poder), acredita-se que as relações que se estabelecem entre os agentes/sujeitos/grupos/indivíduos/classes são marcadas pelo predomínio (instável) da igualdade e da diferença e que a dialética entre diferença e igualdade é o que vai estabelecer lugare território como modos geográficos de existência.

Essas relações podem se manifestar de maneira centrípeta (para dentro) e/ou centrífuga (para fora) quando se trata de intersubjetividade e modos de existência frente ao diferente e/ ou ao igual (a mim). $\bigcirc$ modo como agentes/sujeitos/grupos/indivíduos/classes vão reagir ao 
outro é, enfim, o que "ser lugar" ou "ser território" manifestam como essência nas mais diversas escalas espaço-temporais. Quando nos voltamos intencionalmente para dentro e nos colocamos entre iguais ou quando estamos voltados para fora e entre diferentes é possível perceber a constituição de momentos e princípios existenciais dialeticamente relacionados, mas distintos como manifestações do ser-no-mundo.

Isso pode ser percebido, por exemplo, a partir da análise das estratégias e táticas de apropriação dos espaços públicos urbanos, relacionando os conceitos de lugar e território às diferentes maneiras como os agentes/sujeitos/grupos/indivíduos/classes vão se apropriar de ruas, parques e praias no cotidiano da cidade contemporânea, como se buscou desenvolver na quarta seção deste ensaio. Há aqui, como nos lembra Gaston Bachelard, uma dialética entre interior e exterior, que consideramos fundamental para a compreensão das ideias aqui expostas.

\section{A dialética do exterior e do interior}

Para Bachelard, interior e exterior constituem uma "dialética do esquartejamento", cuja geometria aparentemente evidente nos cega logo que a introduzimos em âmbitos metafóricos. Surge, assim, uma dialética do ser e do não ser. Segundo o filósofo, a metafísica mais profunda se enraíza em uma "geometria implícita" que "espacializa o pensamento" (Bachelard, 1998, p. 215-216). Desse modo, o aquém e o além vão repetir surdamente a dialética do exterior e do interior: "tudo se desenha, mesmo o infinito" (Bachelard, 1998, p. 216).

Nessa dialética, o ser do homem se revela como "ser desfixado": fechado no ser, sempre há de ser necessário sair dele. Apenas saído do ser, há de ser sempre preciso voltar a ele. Bachelard leva aos limites da imaginação as consequências da dialética entre interior e exterior ao afirmar que, "por vezes, é estando fora de si" que o ser pode de fato experimentar "consistências"; por vezes, também, poder-se-ia afirmar que o ser está "encerrado no exterior" (Bachelard, 1998, p. 218).

A dialética do interior e do exterior apoia-se, portanto, em um "geometrismo reforçado", cujos limites podem se constituir em barreiras. Contudo, entre o concreto (o próximo) e o vasto (o distante) nem sempre a oposição é muito clara, porque a relação dialética entre interior e exterior se diversifica e multiplica em inúmeras nuances e matizes. Ambos, interior e exterior, são "íntimos" e estão sempre prontos a "inverter-se" (Bachelard, 1998, p. 221).

Nesse drama da geometria íntima, onde devemos habitar? [...] $\bigcirc$ medo não vem do exterior. Nem tampouco é feito de velhas lembranças. Ele não tem passado. Também não tem fisiologia. Nada em comum com a filosofia da respiração suspensa. O medo é aqui o próprio ser. Então, para onde fugir, onde se refugiar? Para que exterior poderíamos fugir? Em que asilo poderíamos refugiar-nos? $\bigcirc$ espaço é apenas um "horrível exterior-interior" (Bachelard, 1998, p. 221).

Frente a esse contexto, a oposição entre exterior e interior já não pode ser mais "medida" por sua evidência geométrica, já que se faz necessário "colocar o espaço entre parênteses", fazê-lo recuar, "para que sejamos livres no pensamento", em uma atitude radicalmente dialética (Bachelard, 1998, p. 233). É nesse contexto que Bachelard vai se questionar se o exterior não seria uma "intimidade antiga”, ancestral, "perdida nas sombras da memória” (Bachelard, 1998, p. 232). 
Se, por um lado, o excesso de espaço pode nos sufocar muito mais que a sua falta - vertigem exterior versus imensidão interior - frequentemente, por outro lado, é no espaço íntimo de dimensões as mais reduzidas que a dialética do interior e do exterior pode se manifestar com mais força ("há um consolo em nos sabermos na tranquilidade de um espaço estreito" [Bachelard, 1998, p. 231]).

Vemos que, ao subverter, com sua fenomenologia da imaginação, as geometrias presentes na dialética entre exterior e interior, Bachelard abre caminho, também, a nosso ver, para pensar lugar e território não mais associados a ordens de grandeza ou escalas específicas, dando-nos liberdade para pensá-los, ambos, como vastos e íntimos; e para estabelecer uma dialética existencialista possível entre ser lugar e ser território como modos de manifestação do ser-no-mundo.

O sentido de ser-no-mundo assumido nesta discussão remete à possibilidade de uma ontologia espacial que relacione experiência e processos espaciais específicos: quer dizer, sobretudo, que os agentes/sujeitos/grupos/indivíduos/classes estão implicados nesses processos e que é fundamental, para o desenvolvimento de uma reflexão geográfica, relacionar experiências cotidianas (pré-científicas) de apropriação/criação/produção de espaço com a elaboração conceitual de noções caras à geografia acadêmica, como lugar e território.

\section{Afinando a discussão existencialista de lugar e território, uma digressão}

Uma abordagem existencialista de lugar e território deve radicalizar a dialética das contradições que se colocam para o exercício proposto, buscando contrapor pares de categorias visando à sua superação.

Senão vejamos: de uma maneira bem simples, e com palavras do dia a dia, poderíamos afirmar que território tem a ver com posse e domínio, lugar tem a ver com amor, compromisso e senso de responsabilidade. Temos ciúmes do lugar e defendemos por meio de limites e fronteiras o território. Defendemos o território contra outros territórios; já o lugar não se defende, ele sobrevive pela abertura, pela interconexão em rede, tecendo uma intersubjetividade, que, dialeticamente, supera a posse e a autodefesa pelo abrir-se para o mundo em diferentes escalas espaço-temporais.

Por outro lado, um mundo interconectado por uma rede mundial de computadores nos leva a pensar que a internet e o território têm algo em comum: ambos surgem em contexto estratégico-militar. Mas a internet pode ser apropriada de modo tático/prático por grupos alternativos e contra-hegemônicos (Serpa, 2011).

A análise das táticas de apropriação socioespacial dos meios de comunicação em Berlim e Salvador, protagonizadas por grupos e iniciativas que compõem o tecido sociocultural dos bairros e distritos nas duas cidades, apresentada no livro Lugar e Mídia, nos ajudou a revelar que os lugares são enunciados a partir de representações espaciais coerentes com as trajetórias desses agentes nos respectivos locais de ocorrência. Essas representações são construídas no cotidiano destas áreas a partir de elementos sociais, históricos, econômicos e culturais de seus respectivos espaços de atuação e são também influenciadas pelo acesso desses grupos e iniciativas aos meios de comunicação, condição primeira para a produção de conteúdos sobre o "lugar". 
Enunciar lugares pressupõe que as representações espaciais sejam "comunicadas", daí a importância do acesso às técnicas de comunicação e sua apropriação como tecnologia. E o discurso dos grupos e iniciativas analisados não está nunca isolado do contexto de enunciação, revelando ainda que os lugares enunciados não podem ser compreendidos como objetos dados. O lugar é sempre processual e articula diferentes espaços de conceituação. Essa articulação de recortes/escalas geográficas (do local ao global) será tanto mais ampla como mais complexa conforme a capacidade de articulação dos grupos envolvidos, assim como sua acessibilidade ao meio técnico disponível em cada lugar concreto.

Lugar e mídia: o lugar que se produz pela ação e pelo discurso, em diferentes escalas espaço-temporais, cujos agentes/sujeitos se apropriam da internet como técnica e tecnologia (de processo), produzindo contra-hegemonias. $\bigcirc$ par dialético lugar e território (sim, na abordagem aqui exposta, lugar e território se constituem em relação, no cotidiano, dialeticamente) é complementado por outros pares dialéticos: igualdade/diferença, exterior/interior, hegemonia/contra-hegemonia.

O território é a diferença fragmentada, "estilhaçada"; o lugar, a diferença que "negocia" escalas com os meios de que dispõe (para, no caminho, juntar os "estilhaços"). Se o lugar tende à universalidade, o território tende à particularidade. Transitar entre lugar e território significa finalmente negociar o singular e o universal, buscar superar o particular em direção ao universal, dialeticamente.

$\bigcirc$ lugar pode se tornar território? $\bigcirc$ território pode se converter em lugar? Como lugar e território podem ser superados? Através do mundo, ou melhor, das experiências geográficas do ser-no-mundo. Essas experiências geográficas do ser-no-mundo - da presença, como diria Heidegger (ou mesmo Lefebvre ${ }^{2}$ - se revelam por meio da ocupação, do habitar o mundo, em suma, do apropriar-se do espaço, produzindo espaço:

Enquanto ocupação, o ser-no-mundo é tomado pelo mundo de que se ocupa. [... A Ao dirigir-se para... e apreender, a presença não sai de uma esfera interna em que antes estava encapsulada. Em seu modo de ser originário, a presença já está sempre "fora", junto a um ente que lhe vem ao encontro no mundo já descoberto. E o deter-se determinante junto ao ente a ser conhecido não é uma espécie de abandono da esfera interna. [...] Nesse "estar fora", junto ao objeto, a presença está "dentro", num sentido que deve ser entendido corretamente, ou seja, é ela mesma que, como ser-no-mundo conhece. [...] Quando, em sua atividade de conhecer, a presença percebe, conserva e mantém, ela, como presença, permanece fora (Heidegger, 2012, p. 108-109, grifos no original).

2 Para Lefebvre (2016), a presença só se realiza em situação, mas não podemos afirmar que não há situação sem presença, já que, com efeito, a distância, a separação, o alijamento e o silêncio também definem situações. Aqui, o conceito de situação remete, portanto, ao plano das representações vistas "não só como resultados da separação, mas também como agentes dessa dissociação e como confrontação, reunindo as tendências que provêm da tríplice raiz do desejo": sentir, saber e dominar (Lefebvre, 2006, p. 295). O conceito de situação explicitado em A presença e a ausência (2006) revela também as influências de base fenomenológica na teoria das representações e da produção do espaço de Lefebvre, em especial da fenomenologia descritiva de Merleau-Ponty, mas também das reflexões de Heidegger, Bachelard e Sartre, permitindo a Lefebvre articular conceitos de espaço percebido, espaço concebido e espaço vivido, a partir de noções caras à fenomenologia: percepção, corporeidade, viver, morar e imaginar, embora Lefebvre critique a abordagem fenomenológica em algumas de suas obras, como explicitado por Schmid (2012, p. 107). 
Estamos novamente aqui diante da dialética entre interior e exterior, entre "dentro" e "fora", pensados em uma perspectiva existencialista. Mas, por outro lado, é necessário reconhecer que essa ocupação, esse habitar o mundo, se complexificou em termos existenciais, articulando lugares e territórios "em rede", por meio da apropriação da técnica e da tecnologia; que as experiências geográficas na contemporaneidade são permeadas por múltiplas territorialidades/lugaridades; que em uma escala pode-se habitar o mundo como território e, em outra escala, como lugar; que a presença articula multiterritorialidades e multilugaridades.

Aqui se abre um pequeno parêntese para, com Relph (2012), afirmar que a lugaridade é a qualidade "própria de lugar" e está fundada na autenticidade e no encontro, no sentido e no espírito de lugar etc. A lugaridade se exprime por meio de uma gradação, sendo mais forte ou mais fraca a depender dos diferentes contextos e situações espaço-temporais. Como territorialidades, no plural, assume-se aqui a definição de Souza (1995), como as qualidades específicas dos territórios (territórios contínuos exprimem, sobretudo, uma continuidade, uma extensão contínua, por exemplo).

Então, mais do que pensar a priori o território como "extenso", área, zona ou território-rede, em contraponto a lugar como "ponto no extenso" (Haesbaert, 2014, p. 45), deve-se estar atento às suas manifestações (e qualidades) nos modos como ocupamos e nos apropriamos do espaço, nas diferentes escalas e situações espaço-temporais; deve-se estar atento, sobretudo, às diferentes maneiras como se articulam lugaridades e territorialidades nos processos contemporâneos de produção/criação do espaço.

É disso certamente que fala Relph (2012, p. 31) ao afirmar que sua experiência de lugar é a um só tempo "intensamente local" e "sem limites", reconhecendo a importância das tecnologias modernas para a emergência de novas experiências geográficas do ser-no-mundo. Para Relph (2012), o ser é:

[...] sempre articulado por meio de lugares específicos [...] $\bigcirc$ lar, e na verdade todo lugar, não é delimitado por limites precisamente definidos, mas, no sentido de ser o foco de intensas experiências, é ao mesmo tempo sem limites. Lugar é onde conflui a experiência cotidiana, e também como essa experiência se abre para o mundo (Relph, 2012, p. 29).

\section{Como lugar e território se exprimem no espaço público da cidade contem- porânea?}

Para dar continuidade à reflexão aqui proposta é necessário agora acionar um terceiro conceito, ou melhor, outro modo geográfico de existência, nos moldes como aqui proposto, buscando-se relacionar lugar e território à maneira como o ser-no-mundo se expressa e manifesta no espaço público, ora se territorializando, ora se "lugarizando", em diferentes contextos e situações.

\section{Território e espaço público: parques e praias}

Como analisado em outras ocasiões (Serpa, 2007, 2013a, 2013b), os processos de apropriação do espaço público na cidade contemporânea são condicionados por representações segregacionistas, que vão mediar processos de territorialização de grupos sociais (classes e frações de classe), a partir de uma dialética entre capital cultural e capital econômico (Bourdieu, 2007). 
Nos "novos" e "renovados" espaços públicos urbanos em todo o mundo, as práticas espaciais inscrevem-se num processo de "territorialização do espaço": os usuários se apropriam do espaço público pela instituição de limites e/ou barreiras de cunho simbólicos, às vezes "invisíveis". É assim que o espaço público se transforma em uma justaposição de espaços territorializados; ele não é compartilhado, mas, sobretudo, dividido entre os diferentes grupos e agentes. Consequentemente, a acessibilidade não é mais generalizada, mas limitada e controlada simbolicamente. Falta interação entre esses territórios, percebidos (e utilizados) como uma maneira de neutralizar o "outro" em um espaço que é acessível - fisicamente - a todos.

Assim, as diferenças se traduzem em táticas "exclusivistas" de territorialização, abrindo caminho para o estabelecimento de formas nuançadas de segregação, como atos de vontade que impossibilitam o convívio "entre diferentes" e negam o "outro" pela indiferença e autoisolamento (em geral voluntário) de grupos e indivíduos no espaço público. A necessidade de anonimato se traduz, portanto, em indiferença frente ao "outro", que não compartilha dos laços de intimidade/identidade dos indivíduos e grupos territorializados.

Se o espaço público é o espaço de encontro de diferentes e os territórios são, muitas vezes, espaços de iguais, juntos, mas separados por limites e barreiras simbólicas, então, um parque público em Paris ou uma praia em Salvador, por exemplo, são só aparentemente acessíveis a todos. Todo mundo parece estar ali com todo mundo, porém, de fato, está todo mundo ali, mas com seus limites e barreiras muito bem demarcados, uns em relação aos outros: ler esses limites e barreiras em um domingo ensolarado é uma aula muito elucidativa de como o território representa hoje exatamente o contrário da ideia de espaço público.

Os territórios que se estabelecem no espaço público, e que vão marcar diferenças/desigualdades relativas aos modos de consumo e estilos de vida dos diferentes grupos e classes, têm também, por outro lado, expressão material, ainda que de modo momentâneo e ainda que se trate também de uma "projeção espacial de relações de poder" (Souza, 2009). No entanto, essas relações de poder não caracterizam, de modo geral, a emergência de uma esfera pública urbana, uma atuação política dos grupos e classes sociais no espaço público da cidade contemporânea: revelam, ao contrário, processos de segregação baseados em limites/barreiras que vão impor uma incipiente ou mesmo nula interação social e espacial entre os agentes que se apropriam do espaço.

Esses territórios, condição e reflexo de processos de segregação de cunho simbólico e material, que são em geral efêmeros e móveis, se manifestam em diferentes escalas e recortes e podem ser lidos efetivamente nos espaços públicos urbanos, colocando em xeque, inclusive, a noção mesma de espaço público, como espaço de mediações, lugar por excelência do uso da "razão como emancipação" (Habermas, 1984) ou como "espaço da ação política" (Arendt, 2000).

\section{Lugar e espaço público: a rua}

Retomemos também o que trabalhamos em outras oportunidades (Serpa, 2013c, 2016), para discutir, ainda que brevemente, a relação entre lugar e espaço público. Para sublinhar a profundidade da crise urbana atual, bem como a perplexidade e a incerteza que a acompanham, Henri Lefebvre propôs uma confrontação radicalmente dialética de argumentos a favor 
da rua, mas também contra ela. Entre os argumentos favoráveis à rua está aquele que a define como lugar do encontro, do movimento, da mistura. A rua contém aquelas funções negligenciadas pelo modernismo de Le Corbusier: informativa, simbólica e lúdica. Lugar da "desordem" ou da possibilidade de uma "nova ordem", do acontecimento revolucionário e da troca pelas palavras e signos (Lefebvre, 2004).

Contra a rua, poder-se-ia dizer, sob essa ótica, que se tornou o lugar privilegiado da repressão possibilitada pelo caráter "real" das relações que aí se estabelecem. O passar pela rua é ao mesmo tempo obrigatório e reprimido. Se a rua já foi o lugar de encontro por excelência, hoje se converte em rede organizada pelo/para o consumo, em passagem de pedestres encurralados e de automóveis privilegiados, em transição obrigatória entre o trabalho, os lazeres programados e a habitação. Embora palco para os grandes eventos permitidos e estimulados pelo poder público (carnaval, shows, espetáculos, festivais), é também objeto das forças repressivas que impõem o silêncio e o esquecimento à verdadeira apropriação: a da "manifestação" efetiva.

Jane Jacobs defende que as ruas e calçadas são os "órgãos mais vitais" de uma cidade. Entre suas funções estaria a manutenção da segurança urbana: segundo Jacobs (2003), os casos de violência em uma rua ou um distrito fazem com que as pessoas temam e "usem" menos esses espaços, tornando-os ainda mais inseguros. Ou seja, esvaziar as ruas, evitá-las, se autossegregar em shoppings e condomínios fechados é, ao contrário do que pressupõe o senso comum, a pior maneira de vencer a delinquência e a criminalidade. Só ocupando as ruas e reforçando as redes de controle social cotidiano é possível combater de fato o que chamamos de "violência urbana" (Jacobs, 2003).

As manifestações ocorridas em junho de 2013 nas cidades brasileiras mostraram a força das ruas e as possibilidades que esses espaços oferecem - ao menos potencialmente - para a vida urbana em seu sentido mais político e social. Demonstram também que a dialética entre ordem e desordem que se expressa em tais manifestações talvez seja necessária para a articulação de novas formas de organização da vida urbana, revelando ainda os limites e desafios para todos aqueles que desejem se reapropriar desses espaços de forma não segregacionista ou exclusivista.

Esses ativismos que se manifestam nas ruas brasileiras contrariam a ideia de que, na cidade contemporânea, não existiria mais "aqui", tudo seria "agora", em decorrência da compressão do tempo e da aceleração das velocidades. De que tudo aconteceria sem que fosse necessário ir ao encontro dos seres à nossa volta, ir aos lugares que nos rodeiam. A interação virtual parecia superar, para alguns teóricos sociais como Paul Virilio (1999), toda ação e todo ato concreto.

No entanto, essas manifestações vêm extrapolando o espaço virtual das redes sociais em direção aos espaços urbanos "concretos", dando novos sentidos aos ativismos sociais urbanos, como coletivos articulados em rede que tecem sua trama na cidade (Serpa, 2016). Nesse contexto, que consequências essa retomada política das ruas tem para a territorialização/a "lugarização" da cidade pelo corpo? ○ que representaria afinal essa (re)inserção dos corpos na cidade para além das dimensões políticas e sociais envolvidas nessas manifestações? 


\section{O corpo reinserido na cidade: uma segunda digressão}

Para discutir o corpo (re)inserido na cidade, no espaço público da cidade contemporânea, é preciso antes de tudo admitir, com Merleau-Ponty, que o espaço corporal e o espaço exterior constituem uma unidade dialética, um sistema prático, e que "é evidentemente na ação que a espacialidade do corpo se realiza, e a análise do movimento próprio deve levar-nos a compreendê-la melhor" (Merleau-Ponty, 2006, p. 149).

É, sobretudo, a consideração do corpo em movimento que permite a compreensão de como esse corpo habita um espaço (e também um tempo), "porque o movimento não se contenta em submeter-se ao espaço e ao tempo, ele os assume ativamente, retoma-os em sua significação original, que se esvai na banalidade das situações adquiridas" (Merleau-Ponty, 2006, p. 149). O corpo em movimento na cidade, em suas estratégias de apropriação dos espaços urbanos, constitui uma experiência, revelada "sob o espaço objetivo, no qual finalmente o corpo toma lugar, uma espacialidade primordial da qual a primeira é apenas o invólucro e que se confunde com o próprio ser do corpo".

Para Merleau-Ponty, o ser corpo "é estar atado a um certo mundo, e nosso corpo não está primeiramente no espaço: ele é no espaço" (Merleau-Ponty, 2006, p. 205). Isto sublinha também o corpo como "aberto e poroso ao mundo", embora não seja esse em geral o modo de ver o corpo na tradição ocidental dominante, como nos lembra o geógrafo David Harvey (2004, p. 138).

Se o corpo só "é" no espaço, se o "ser corpo" é sempre "ser corpo no mundo", precisamos também admitir que espaço e mundo - e aqui podemos pensar o mesmo para território e lugar - são construções humanas e não externalidades objetivas e estritamente "materiais". Espaço e mundo se constituem dialeticamente como produto e processo, como experiência humana corporificada.

Espaço e mundo são experiências/conceitos que só se realizam por processos relacionados ao ser-no-mundo, como territorialização e "lugarização", de acordo com o que nos propomos a discutir neste ensaio; portanto, territorialização e "lugarização" produzem/criam espaço e mundo. A dialética entre espaço e mundo, por sua vez, encontra sua realização justamente nos processos de "lugarização" e territorizalização: ao se territorializar/"lugarizar", se apropriando e criando espaço, o ser-no-mundo também cria "mundos" existenciais próprios e corporificados no espaço e no tempo. Pode-se assim afirmar que a dialética espaço-mundo se realiza e define pela dialética entre lugar e território, tomados como experiências do ser-no-mundo, dialética e estreitamente relacionadas.

Por outro lado, se o corpo não é uma entidade "fechada e lacrada", mas algo relacional, criado, delimitado e sustentado por fluxos espaço-temporais e múltiplos processos, então "o conjunto de atividades performativas disponíveis ao corpo num dado tempo e lugar não são independentes do ambiente tecnológico, físico, social e econômico em que esse corpo tem de ser" (Harvey, 2004, p. 137).

Mas a humanidade não é uma soma de indivíduos, como ensina Merleau-Ponty, muito menos um ser único no qual a pluralidade dos indivíduos estaria fundida e destinada a se incorporar (Merleau-Ponty, 2004, p. 49-50). $\bigcirc$ mundo, o espaço e a cidade são construções humanas plenas de relações entre sujeitos, construções radicalmente intersubjetivas. Afinal, 
"só sentimos que existimos depois de já ter entrado em contato com os outros, e nossa reflexão é sempre um retorno a nós mesmos que, aliás, deve muito à nossa frequentação do outro" (Merleau-Ponty, 2004, p. 48).

Sob essa ótica, só conheço os outros seres humanos por meio de seus gestos, de suas palavras, de seus olhares, ou seja: só posso conhecê-los por meio de seus corpos: "os outros são para nós espíritos que habitam um corpo, e a aparência total desse corpo parece-nos conter todo um conjunto de possibilidades das quais o corpo é a presença propriamente dita" (Merleau-Ponty, 2004, p. 43).

\section{Para não concluir: ser lugar e ser território como manifestações da política?}

Corpo e lugar estão profundamente imbricados como mostram as pesquisas de Brito (2016, p. 54, grifos no original), para quem o "corpo-lugar que se desloca e se relaciona", ao mesmo tempo "se constrói, a partir das experiências vividas. No corpo, apesar das mudanças espaciais, os lugares se tornam vivos por meio da memória, dos rastros e marcas deixados nele". Trabalhando na interface entre teatro, geografia e fenomenologia, Brito (2016) coloca os corpos-lugares de atores profissionais em movimento nos "lugares cênicos" encontrados às margens de grandes avenidas em Salvador, por meio de "intervenções viárias" e entrevistas com os artistas participantes dessas experiências:

Ver o entrevistado se desnudar, se revelar a partir de sua relação com os lugares que ele identifica como formadores de sua construção como pessoa se faz importante para o que definimos como corpo-lugar: uma cadeia de sensações, histórias, dados e memórias que o indivíduo armazena ao longo da vida a partir dos lugares onde ele vive/viveu. Esses lugares podem ser uma multiplicidade de cidades, estados, países ou localidades, ou mesmo bairros de uma única cidade. Cada lugar tem suas características, peculiaridades, cultura e hábitos, e o que fica no corpo de cada um é o que vai possibilitando a constituição desse corpo-lugar, que, no caso do artista, produz repertório, vocabulário e estados de emoção que esse artista pode acionar, quando necessário, em seus processos criativos (Brito, 2016, p. 58, grifos no original).

As pesquisas de Brito (2016) mostram também que corpos-lugares podem ser acionados no cotidiano urbano como práticas de resistência política, vivendo a cidade e todas as suas contradições ao intervir em suas vias e lugares de maior fluxo. A intenção de Brito (2016) com essas experiências era a de revelar a posição criadora e a participação cidadã do ator, um "desejo de pensar uma prática urbana para atores, como possibilidade de experimentar uma metodologia que, a partir da ocupação e da transformação de lugares em lugares-cênicos, contemplasse também o trabalho do ator no processo de criação de personagens" (Brito, 2016, p. 120, grifos no original). Nesse contexto, "a intervenção viária não propõe uma ruptura nos fluxos urbanos, mas sim pausas no movimento da cidade; e essas pausas, para quem transita na cidade, se tornam momentos poéticos, lúdicos, mas também reflexivos e críticos da própria cidade" (Brito, 2016, p. 120-121, grifos no original). 
O sentido político e cidadão do ser lugar no mundo, revelado pelas experiências teatrais e geográficas relatadas nos parágrafos anteriores, enfatiza, em última instância, as ligações inextricáveis entre ser e lugar, já que o lugar é onde "cada um de nós se relaciona com o mundo e onde o mundo se relaciona conosco" (Relph, 2012, p. 31). E o que ocorre em cada lugar é "parte de um processo em que o mundo inteiro está de alguma forma implicado. Isso é muito existencial e ontológico. Mas é também econômico e social, pois em toda parte estamos presos em maior ou menor grau nas forças neoliberais e da globalização" (Relph, 2012, p. 31).

Voltemos às manifestações de 2013 nas cidades brasileiras. No documentário Arte Ativa, veiculado no canal Arte 1, uma das entrevistadas expôs seus sentimentos em relação à ocupação das ruas naquele momento, afirmando uma "alegria de se manifestar (na rua) mas não se sabendo exatamente o por quê". Mas, um tanto decepcionada ao fazer esse retrospecto, ela também vai constatar que "de repente aquilo baixou e não voltou", não sem alguém a seu lado no momento da entrevista retrucar em alto e bom som: "mas vai voltar!".

A retomada das ruas em tempos de redes sociais virtuais foi um fato alvissareiro que emergiu dos eventos juninos naquele ano de 2013. Em artigo publicado no jornal A Tarde, Antônio Risério (2013, p. A2) traça uma interessante relação entre as redes sociais e as ruas, destacando um processo de retroalimentação positiva entre os mundos real e virtual. Aliás, Salvador é vanguarda em ativismos; assim, basta lembrar-se do movimento Desocupa, que começou nas redes sociais em defesa de uma praça no bairro de Ondina, localizado na orla atlântica da cidade, e se expandiu para outras esferas e dimensões (Serpa, 2016).

De fato, essas manifestações - pelo menos do modo como ocorreram em 2013 - sofreram um processo de refluxo, mas é inegável também que repercutem até hoje no momento político das cidades e do país, já que se ocuparam posteriormente as ruas, mas numa atitude muito mais de radicalização das diferenças, territorializadas no espaço de forma segregacionista e com pouco ou nenhum diálogo entre grupos com opiniões e posições políticas divergentes (manifestações pró e anti-impeachment da presidente da República, por exemplo, separadas por uma grade em plena Esplanada dos Ministérios, em Brasília).

Vemos que, com a falta do diálogo entre diferentes, a esfera pública retrocede e o público se revela, contraditoriamente, como íntimo e particular, territorializado, enquanto o lugar se recolhe à esfera mais privada e íntima, que se torna (radicalmente) "lugarizada". Então, a desterritorialização dos corpos via redes virtuais, num primeiro momento, em 2013, lugariza nas ruas os manifestantes pela "alegria de manifestar" entre diferentes, para, a seguir, os territorializar em manifestações separadas, segregadas, com o ser território assumindo preponderância frente ao ser lugar nos processos (mais ou menos) políticos de apropriação do espaço público nas cidades brasileiras.

Comentando as manifestações de junho de 2013, Risério (2013, p. A2) afirma que "da rede à rua, gentes se mobilizam de um dia para outro. Da rua à rede, alguém logo ao chegar em casa, pode postar uma foto que sensibilize milhares de pessoas". Isso coloca para nós uma nova realidade, de "espaços essencialmente reversíveis". No contexto aqui discutido, da reinserção do corpo na cidade, interessa particularmente a afirmação de que a "rua é o lugar do coração batendo, do sangue circulando, da respiração percebida, da emoção", em contraponto ao (e também em relação com o) espaço virtual dos signos e do discurso (Risério, 2013, p. A2). 
Ainda nesse contexto, Risério (2013, p. A2) defende a ideia de que "na rua o que conta é a leitura do espaço e a inteligência do corpo". Ou seja, confluindo para a posição aqui também defendida de que a rua é o espaço por excelência da plenitude do corpo, para corpos em situação, construindo/criando espaços de intersubjetividade no "corpo a corpo" sem mediações. Então, ao contrário do que prognosticou Virilio (1999), há uma interação entre redes e ruas que se retroalimentam de modo a criar novas possibilidades de manifestação no espaço público na cidade contemporânea.

Mas é também fundamental compreender esses processos políticos como manifestações (contraditórias) do ser lugar e do ser território no mundo, de um corpo situado - lugarizado e/ou territorializado - no mundo, que essas manifestações se dão em diferentes escalas e esferas de "intimidade" e "abertura" no/para o mundo, e que, finalmente, exprimem ações e discursos diferenciados de agentes/sujeitos/grupos/indivíduos/classes, que, ao se manifestarem, manifestam também sua atitude de ser lugar ou ser território frente ao outro.

Por fim, reafirmamos o sentido de ser-no-mundo assumido neste ensaio, baseado, sobretudo, em uma ontologia espacial primeira e fundadora (geograficidade) que deve ser sempre explicitada nas elaborações conceituais em geografia, como argumentam Relph (1985) e Marandola Jr. (2012), ambos inspirados em Heidegger. Busca-se, com essa postura ontológica, colocar em movimento os conceitos de lugar e território, libertando-os de certo imobilismo que empobrece a priori suas possibilidades de aplicação na reflexão geográfica.

\section{Referências}

ALMEIDA, M. G. Fronteiras sociais e identidades no território do complexo da usina hidrelétrica da Serra da Mesa, Brasil. In: BARTHE-DELOISY, F; SERPA, A. (Org.). Visões do Brasil: estudos culturais em geografia. Salvador: EDUFBA, 2012. p. 145-166.

ARENDT, H. A condição humana. 10. ed. Rio de Janeiro: Forense Universitária, 2000.

BACHELARD, G. A poética do espaço. São Paulo: Martins Fontes, 1998.

BOURDIEU, P. A distinção: crítica social do julgamento. São Paulo: Edusp; Porto Alegre: Zouk, 2007.

BRITO, M. S. O teatro que corre nas vias. Tese (Doutorado em Artes Cênicas) - Escola de Teatro, Universidade Federal da Bahia, Salvador, abr. 2016.

DARDEL, E. O homem e a terra. São Paulo: Perspectiva, 2011.

HABERMAS, J. Mudança estrutural da esfera pública. Rio de Janeiro: Tempo Brasileiro, 1984.

HAESBAERT, R. Viver no limite: território e multi/transterritorialidade em tempos de insegurança e contenção. Rio de Janeiro: Bertrand Brasil, 2014.

HARVEY, D. Espaços de esperança. São Paulo: Loyola, 2004.

HEIDEGGER, M. Ser e tempo. 6. ed. Petrópolis: Vozes; Bragança Paulista: Ed. Universitária São Francisco, 2012. 
JACOBS, J. Morte e vida de grandes cidades. São Paulo: Martins Fontes, 2003.

LEFEBVRE, H. La presencia y la ausencia: contribución a la teoría de las representaciones. México. Fundo de Cultura Econômica, 2006.

LEFEBVRE, H. A revolução urbana. 2. reimpr. Belo Horizonte: Ed. UFMG, 2004.

La production de 1'espace. 4. ed. Paris: Anthropos, 2000.

LÉVY, J.; LUSSAULT, M. Dictionaire de la Géographie et de 1'Espace des Societés.

Paris: Belin, 2003.

MARANDOLA JR., E. Heidegger e o pensamento fenomenológico em geografia. Geografia, Rio Claro, v. 37, n. 1, p. 81-94, jan./abr. 2012.

MERLEAU-PONTY, M. Fenomenologia da percepção. 3. ed. São Paulo: Martins Fontes, 2006.

Conversas - 1948. 3. ed. São Paulo: Matins Fontes, 2004.

RELPH, E. Reflexões sobre a emergência, aspectos e essência do lugar. In: MARANDOLA JR., E.; HOLZER, W.; OLIVEIRA, L. (Org.). Qual o espaço do lugar?. São Paulo: Perspectiva, 2012. p. 17-32.

Geographical experiences and being-in-the-world: the phenomenological origins in Geography. In: SEAMON, D.; MUGERAUER, R. (Ed.). Dwelling, place and environment: towards a phenomenology of person and world. New York: Columbia University Press, 1985. p. 15-31.

. As bases fenomenológicas da geografia. Geografia, Rio Claro, v. 4, n. 7, p. 1-25, 1979.

RISÉRIO, A. Entre as redes e as ruas. A Tarde, Salvador, 20 jul. 2013. p. A2.

SCHMID, C. A teoria da produção do espaço de Henri Lefebvre: em direção a uma dialética tridimensional. Geousp - Espaço e Tempo (Online), São Paulo, v. 32, p. 89-109, 2012.

SERPA, A. Um coletivo em rede construindo alternativas políticas para a cidade: o Desocupa Salvador. In: ROLNIK, R.; FERNANDES, A. (Org.). Cidades. Rio de Janeiro: Funarte, 2016. p. 481-502. v. 1.

._Microterritórios e segregação no espaço público da cidade contemporânea. Cidades, Presidente Prudente, v. 10, p. 61-75, 2013 a.

Segregação, território e espaço público na cidade contemporânea. In: VASCONCELOS, P. A.; CORREAA, R. L.; PINTAUDI, S. M. (Org.). A cidade contemporânea: segregação espacial. São Paulo: Contexto, 2013b. p. 169-188.

Espacialidade do corpo e ativismos sociais na cidade contemporânea. Mercator (Fortaleza. Online), v. 12, p. 23-30, 2013c.

Lugar e Mídia. São Paulo: Contexto, 2011. 
O espaço público na cidade contemporânea. São Paulo: Contexto, 2007.

SOUZA, M. L. "Território" da divergência (e da confusão): em torno das imprecisas fronteiras de um conceito fundamental. In: SAQUET, M. A.; SPOSITO, E. S. (Org.). Territórios e territorialidades: teorias, processos e conflitos. São Paulo/Presidente Prudente: Expressão Popular, 2009. p. 57-72.

O território: sobre espaço e poder, autonomia e desenvolvimento. In: CASTRO, I. E.; GOMES, P. C. C.; CORREAA, R. L. (Org.). Geografia: conceitos e temas. Rio de Janeiro: Bertrand Brasil, 1995. p. 77-116.

VIRILIO, P. A bomba informática. São Paulo: Estação Liberdade, 1999. 